\title{
Aprendizagem nos tempos atuais, tecnologia, emoções, pandemia
}

Learning in current times, technology, emotions, pandemic

Aprendizaje en los tiempos actuales, tecnología, emociones, pandemia

Liliane Musumeci Ferreira ${ }^{1}$

ORCID: https://orcid.org/0000-0001-8749-0652 Universidade Columbia del Paraguay, Paraguai

E-mail: lilianemusumeciferreira@gmail.com

Aline dos Santos Moreira de Carvalho

ORCID: https://orcid.org/0000-0001-9965-9566

Universidade Columbia del Paraguay, Paraguai

E-mail: bioaline2017@yahoo.com

José Carlos Guimaraes Junior ${ }^{3}$

ORCID: https://orcid.org/0000-0002-8233-2628

Universidade do Estado do Amazonas, Brasi

E-mail: profjc65@hotmail.com, Brasil

Pedro Carlos Pereira ${ }^{4}$

ORCID: https://orcid.org/0000-0003-4646-0080

Universidade Federal Rural do Rio de Janeiro, Brasil

Universidad Columbia Del Paraguay, Paraguai

E-mail: pecape@ig.com.br

José Luis Monteiro da Conceição ${ }^{5}$

ORCID: https://orcid.org/0000-0003-3496-8311

Grupo Laboratório de Pesquisas e Políticas Linguísticas, Interação e Desenvolvimento Humano, Brasil Grupo Saberes e Práticas Educativas no Campo da Pesquisa Intervenção, Brasil

E-mail: luisuneb1@hotmail.com

Eliane dos Santos Macedo Oliveira ${ }^{6}$

ORCID: https://orcid.org/0000-0002-7523-6558

Universidade Estadual do Oeste do Paraná, Brasil

E-mail: esmacedo879@gmail.com

Léia Flauzina da Silva Albuquerque 7

ORCID: https://orcid.org/0000-0002-6942-1116

Universidade Columbia del Paraguay, Paraguai

E-mail: psicopedagogarjleiaflauzina@gmail.com

Israel Caboclo

ORCID: https://orcid.org/0000-0003-4078-0307

Universidade Columbia del Paraguay, Paraguai

E-mail: israelcaboclomestrado@gmail.com

\footnotetext{
${ }^{1}$ Mestranda em Ciências da Educação pela Universidade Columbia del Paraguay/Instituto IDEIA-Paraguai.

${ }^{2}$ Mestranda em Ciências da Educação pela Universidade Columbia Del Paraguay/Instituto IDEIA- Paraguai.

${ }^{3}$ Doutor em Biodiversidade e Conservação Universidade do Estado do Amazonas-Rede Bionorte

${ }^{4}$ Professor Adjunto da Universidade Federal Rural do Rio de Janeiro/Brasil e Professor Colaborador do Programa de Pós-Graduação

${ }^{5}$ Mestre em Educação. Pedagogo e Licenciado em Letras. Pesquisador do Grupo Laboratório de Pesquisas e Políticas Linguísticas, Interação e

Desenvolvimento Humano- LIDAH. Integrante do Grupo de Pesquisa Formação de Professores, Saberes e Práticas Educativas no Campo da Pesquisa Intervenção.

${ }^{6}$ Mestra em Educação - Unioeste Paraná - Diretora do Colégio Estadual Rancho Alegre

${ }^{7}$ Mestranda em Ciências da Educação pela Universidade Columbia Del Paraguay/Instituto IDEIA- Paraguai.

${ }^{8}$ Mestrando em Ciências da Educação pela Universidade Columbia Del Paraguay/Instituto IDEIA- Paraguai.
} 


\title{
Resumo
}

Estudos e transformações ao longo dos anos no ambiente acadêmico, caminhos inovadores no processo metodológicos para a aprendizagem, entender a que a medicina, a tecnologia, educação podem andar juntas, formando um mundo melhor. O impacto que as doenças transformaram o meio social, político, psíquico, compreensão dos anseios e medos qualificando um futuro melhor. Tecnologias oportunizaram um novo ambiente de sala de aula online, novo momento professor e aluno, novas oportunidades de ensino alguns usufruindo e outros não tendo oportunidade e acesso. Como poder controlar as emoções diante de um novo vírus e tantas mudanças brusca no processo de aprendizagem.

Palavra-chave: Aprendizagem; Tecnologia; Pandemia; Emoções.

\begin{abstract}
Studies and transformations over the years in the academic environment, innovative paths in the methodological process for learning, understanding that medicine, technology, education can go together, creating a better world. The impact that diseases have transformed the social, political, psychological, understanding of anxieties and fears qualifying for a better future. Technologies have created a new online classroom environment, a new teacher and student moment, new teaching opportunities, some enjoying and others not having opportunity and access. How to be able to control emotions in the face of a new virus and so many sudden changes in the learning process.
\end{abstract}

Keyword: Learning; Technology; Pandemic; Emotions.

\section{Resumen}

Estudios y transformaciones a lo largo de los años en el ámbito académico, caminos innovadores en el proceso metodológico para el aprendizaje, entendiendo que la medicina, la tecnología, la educación pueden ir juntas, creando un mundo mejor. El impacto que las enfermedades han transformado la comprensión social, política, psíquica, de las ansiedades y miedos calificando para un futuro mejor. Las tecnologías han creado un nuevo entorno de aula en línea, un nuevo momento para maestros y estudiantes, nuevas oportunidades de enseñanza, algunos disfrutan y otros no tienen oportunidad ni acceso. Cómo poder controlar las emociones ante un nuevo virus y tantos cambios bruscos en el proceso de aprendizaje.

Palabra clave: Aprendizaje; Tecnología; Pandemia; Emociones.

\section{Introdução}

Este artigo tem uma visão metodológica exploratória com caráter descritivo nos estudos dos artigos científicos, os decretos, com o olhar voltado para a construção do processo de aprendizagem e as suas interfaces de evolução social da aprendizagem e tecnologia, visando auxiliar e ajudar a qualificar, indicar caminhos para empoderar e identificar os anseios e medos para um novo cotidiano após pandemia ou final.

Notícias dos estudos científicos divulgou a chegada no Brasil em março de 2020 um vírus COVID-19, onde ocorreu o primeiro caso na China sendo espalhado rapidamente, a ORGANIZAÇÃO DA SAÚDE decretou a PANDEMIA. Impactando diretamente na saúde de toda a população. ONS à Organização Mundial da Saúde declarando situação de EMERGÊNCIA, Internacional para o mundo.

As doenças infecciosas ao longo dos anos, teve grande impacto mudando as ações sociais, político, psicossocial, emocionais, educacionais.

Um momento novo, e o mundo começou novas reorganizações inusitada, na área tecnológica, explorando as ferramentas google classroom (ferramenta assíncrona- não é necessário conexão simultânea), aplicativo ZOOM (ferramenta síncrona-necessário conexão simultânea). Impulsionando a prática pedagógica.

Olhar para o futuro com ações de segurança, com qualidade reorganizando as ações sociais, a medicina na constante busca da vacina para acabar com o vírus ou amenizar os danos.

Reorganização econômica e social para enfrentar a pandemia, engajando nos projetos sociais e aprimorando os recursos tecnológicos.

A atuação de profissionais na educação sendo inovadoras para conseguir alcançar a todos o processo do SABER. Olhar diferenciado ao retorno dentro das instituições de ensino para os envolvidos. 
Repensando nos costumes e hábitos do dia-a-dia, e ver o que realmente é importante em nossas vidas. Sendo difícil para uns e para outros o isolamento social foi maravilhoso, famílias se aproximaram e outras se separaram.

\section{Inovação no Processo da Aprendizagem}

As mudanças significativas no processo de aprendizagem têm chamado a atenção ao acesso de informações para todos, surgindo padrões de protocolos de acesso, conscientizando e minimizando a desigualdade social.

Ocorreu o cancelamento das aulas presenciais em todas as modalidades de ensino e iniciou as aulas online (remota ou ensino à distâncias) muitos professores se adaptando através de aulas plataforma google meet, suporte whatsapp, zoom. Professor sendo tutor on-line buscando compreender novas tecnologias como recursos pedagógicos indicando alternativas.

Com o isolamento social muitas famílias perderam seus empregos ou perderam os responsáveis financeiros, ficando nítido a dificuldade de acesso e a aumento da desigualdade social.

Professor fazendo atividades impressas para o aluno conseguir acompanhar o conteúdo acadêmico, indo na casa de familiares para acompanhar as aulas, assistindo aulas a noite porque o responsável chegava do trabalho com o celular.

Estruturar e reconfiguras as oportunidades sociais para o processo de aprendizagem, proporcionando espaços adequados quando a aula for presencial para não ocorrer a expansão de vírus ou outra doença, ambiente arejado, higiene adequada, números de pessoas proporcional no ambiente.

Regras sanitárias para a saúde, evitando a contaminação direta ou indireta com atitudes constantes para prevenção valorizando a VIDA. A mudança de forma gradativa e significativa a higiene constante das mãos, a utilização de máscaras no rosto (cobrindo nariz e boca) evitando a entrada do vírus.

É importante o ser humano observar a natureza e respeitar, assim poderá prevenir, precisando reconectar, reorientar (rever ações sociais e políticas), resgatar o amor, respeito incluindo e oportunizar para todos. Oportunizando direitos a cultura, igualdade social diminuindo a desigualdade.

Repensar para propiciar a igualdade porque o homem já contribuiu muito para destruir o meio (a poluição da atmosfera do ar, rios, mares, desmatamento alterando o eco sistema).

\section{Como Respeitar as Emoções com Tantas Mudanças Sociais}

Importante a compreensão sobre os manifestos das emoções; estados de alegria, tristeza, medo, risos, choros, fenômenos de características sociais de acordo com o meio em que estão inseridas. Podendo ser espontânea ou nãoespontânea, porque entendemos que o seu humano é social, racional e pensante.

Respeitar o contexto social passado e presente que contribuem os fenômenos das expressões.

As expressões dos sentimentos são despertadas em graus diferentes estimuladas para expressão ao outro ou por conta do outro.

As experiências vividas afetam diretamente na conduta do seu dia-a-dia, afetando diretamente na saúde mental do indivíduo, impacto nos sentimentos de tensão e apreensão tem um alerta na saúde, ocorrendo o pensamento da doença, tempo de duração do vírus e recidiva, as sequelas, a mortalidade, perda de entes queridos e a sua imprevisibilidade.

Tratando por ser um momento de muito estudo cientifico para auxiliar e salvar vidas, um vírus imprevisível com muitas alterações.

Hoje em 2021 ao analisar a história observa que já passamos por doenças como a gripe suína identificada como a pandemia de Influenza H1N1 (subtipo de influenza vírus A) uma gripe em humanos, que passou no período de abril de 2009, com o primeiro caso no México, a forte dimensão espacial e sua agressividade com sequelas na saúde e a ameaça letal. 
O surto do vírus Ebola surgiu em 1976 em Nzara na República Democrática do Congo, apresentando sintomas de febre hemorrágica, vômitos, dores pelo corpo, provoca sangramento em várias partes do corpo, infecta humanos e primatas. Teve aumento considerado transtorno psiquiátrico, aumento do comportamento agressivo.

O vírus coronavírus (COVID-19) infecção em grau leve ou severo afetando a parte respiratória (febre, cansaço, tosse), primeiro caso em 31 de dezembro de 2019 na cidade de Wuhan (China), sendo transmitida por tosse e espirros. Ocorreu um grande aumento de pessoas com transtornos emocionais (o isolamento e mudança de rotina, muitas pessoas não souberam lidar com as novas mudanças).

Reflexão no momento da quarentena: pensar o que realmente precisamos para viver bem, equilibrado, com saúde, hábitos de higiene, olhar para si mesmo e saber aproveitar o tempo ocioso, respirar com calma.

Entender que os transtornos mentais têm grande impacto na vida, problemas da rotina e organização familiares, fechamento das instituições de ensino, trabalho em home-office (trabalhar de casa), isolamento. Provocando a emoção de ansiedade, depressão, medo, tédio, solidão, insônia, raiva em alguns casos evoluindo para transtorno podendo ser psicótico ou até mesmo paranoicos, em graus diferentes baixo ou significativamente altos, para algumas pessoas a sensação de incerteza ou desastre.

Doenças crônicas emocionais sendo estudadas como questão importantíssima para a saúde mental. A depressão que levam ao esgotamento físico e mental ligados diretamente com a conduta do dia-a-dia, chamado de Síndrome de Burnourt (SB) - diagnóstico médico legal com classificação Internacional de Doença (CID-11) da Organização Mundial da Saúde "suporte aos profissionais da saúde". Pensar na prevenção de esgotamento emocional com a intervenção e abordagem necessárias para promoção da saúde e mudanças de sociais mais humanas. Fatores individuais e socioeconômicos específicos do ambiente que estão inseridos interferem diretamente na ação.

Refletir sobre o tempo de atuação profissional - ampliação excessiva da jornada de trabalho, baixa remuneração, excesso de serviço, insegurança para execução das atividades, condições adequadas de trabalho, vulnerabilidade à contaminação biológica ou ambiental. Imprescindível a prevenção e condições de oportunidade e acesso para melhor qualidade de vida, seja ele no ambiente acadêmico ou ambiente diversos.

\section{Alternativas Tecnológicas e Suas Inovações}

Em 17 de março de 2020 o Conselho Nacional de Educação (CNE) publicou no 343 que as aulas presenciais devem ser substituídas pelo ensino a distância (EAD), "aulas em meios digitais enquanto durar a situação de pandemia"

Respeitando as normas prevista no "MINISTRO DE ESTADO DA EDUCAÇÃO", no uso da atribuição que lhe confere o art. 87, parágrafo único, incisos I e II, da Constituição, e considerando o art. $9^{\circ}$, incisos II e VII, da Lei no 9.394, de 20 de dezembro de 1996, e o art. $2^{\circ}$ do Decreto n ${ }^{\circ} 9.235$, de 15 de dezembro de 2017 ”

Normas de conduta para as aulas serem ministrada por meios da tecnologia, alternativa para ocorrer o processo de formação de forma remota, inovando o ambiente e propiciando a aula online (remoto) com interação professor-aluno.

Para entendermos especificações em relação a qualidade na educação adequada temos que ter o reconhecimento de pessoas que vivem em municípios rurais onde o direito e acesso aos estudos acabem fluindo de maneira sólida. O reconhecimento geográfico deve se estender para as necessidades culturais de uma maneira geral para os indivíduos que são identificados como agricultores, extrativistas, ribeirinhos, caiçaras, seringueiros; todo o mecanismo abre o debate para as implicações e ações para a sociedade civil onde a tecnologia é considerada ainda algo muito distante dessas pessoas.

Pesquisas mostram um panorama que tem apontado as principais dificuldades em relação em áreas rurais;

$>$ insuficiência e precariedade das instalações físicas das escolas; 
$>$ dificuldade de acesso a professores e alunos as escolas, em razão de falta de um sistema adequado de transporte escolar.

De acordo com o artigo $28^{\circ}$ que dá o direcionamento especifico como escola de campo que está incluso como educação básica conforme lei 9394/96 - LDB.

Conteúdos curriculares e metodologias apropriadas as reais necessidades e interesse de alunos da zona rural.

Fraquejar a luta pela esperança é tornar como desespero o futuro de uma educação sólida, agora se enxergamos essa luta positivismo fortalecemos o cotidiano para estabelecer uma política pública principalmente de respeito e de qualidade, tratar a educação de áreas rurais como educação que possui um cercado é trata-la como um ponto final do conhecimento, e não podemos esquecer que a palavra educação ela sempre estará ligada ao subjuntivo podemos imaginar e traçar metas das quais oportunizar a quem quer chegar ao um nível superior de educação é não só uma concepção de necessidade, mas de desenvolvimento urbano e socio econômico para as próprias áreas rurais.

É sabido que diante do descaso do poder público alguns municípios passaram a se adaptar ao ensino hibrido atual, mas não deixaram claro quem irá pagar essa conta apesar de existir um regime de colaboração por parte dessa comunidade ou até mesmo por repartição privada, diante do senário se comoveram e aplicaram o que podemos classificar como uma redemocratização qualitativa.

É frequente interpretar um atraso como herança ou fardo recebido de um passado ainda não superado, nessa interpretação o papel da política pública significaria corrigir esses atrasos com políticas compensatórias, mas incentivar e criar condições que podem ultrapassar os olhares imaginários sobre essas áreas rurais é definitivamente assumir uma agenda onde exigir política pública será um caminhar com visão nova e realista tudo isso não deixando os mecanismo da educação se dissiparem para o outro caminho que é da precarização.

Revitalizar o reforçar governos para garantir será o avanço dentro de uma universalização onde o direito público será aplicado de forma supressiva pela gestão e mais o funcionamento educacional será marcada pela conscientização juntos ao projeto da infância e da juventude existente e moldado de acordo com a cultura e economia de cada município de área rural.

A tecnologia mostra-se importantíssima para interação, comunicação, aulas remotas, trabalhos remotos para proporcionar o processo de formação eficaz. Olhar voltada para a inclusão digital para todos, oportunizando a saúde física e mental do indivíduo.

Condições de acesso ficando explicito as diferenças sociais, a desigualdade do mundo, não tem o computador, celular, acesso à internet, ocorrendo a desigualdade digital.

Segundo Conforto e Vieira (2015, p. 45):

A abundância de recursos e de conte dos físicos e digitais, aliada ampliação dos serviços de conexão móvel com a Internet, de armazenamento em nuvem e a evolução da telefonia celular, promoveram o surgimento de uma nova modalidade de educação, a Aprendizagem Móvel.

Necessário respeitar o contexto social e propiciar a transformação da tecnologia e suas inovações com qualidade e oportunidade. Importante o investimento permanente na qualificação profissional da educação, assim oportunizar os alunos com aulas remotas eficaz, treinamento adequado, ferramentas, planejamento para que a tecnologia realmente ajude sem exclusão. Perceber que o celular não é somente para atender ligação, sim entretenimento, ferramenta de trabalho, ferramenta de estudo.

As interfaces do processo educacional e tecnológicos podem ser inovadores e transpor o ensino o remoto, propiciar uma prática afetiva respeitando a formação eficaz de acordo com o contexto social. 
A plataforma google classroom utilizado no ensino a distância, com metodologia de agir na interação ativa como ferramenta online para facilitar a interação de aprendizagem (criar atividade, postar em diferentes momentos, salvar, programar, arquivar, classificar-pontuar, flexibilizar horário). Podendo ser utilizada em diversas instrumento tecnológico smartphones, tablets, computador, celulares.

O Zoom é um aplicativo de teleconferência, videoconferência propiciando reuniões em vídeo, possibilita compartilhar arquivos de textos e imagens durante a chamada. Potencializando o processo de aprendizagem, permitindo até 1.000 pessoas participar, permitindo 49 vídeos na apresentação da tela

Aula hibrida é um ensino com estratégia intercalando os recursos digitais e o ensino presencial.

Aulas com interação de forma síncrona ou assíncrona permite o caminhar ao saber de forma presencial temporária, aulas personalizadas configurando e reconfigurando a didática para realmente atingir o aluno. Estratégias de recursos e saberes para realmente ocorrer o processo formativo.

\section{Considerações Finais}

Estudos cientificos mostrou mais uma vez que a ciência pode salvar e curar vidas, precisamos ofertar igualdade de oportunidade para todos ter um futuro melhor.

Aproveitar e potencializar a construção de um mundo digno para todos, com as mesmas oportunidades sociais, educacionais, políticas, emocionais.

Ações e projetos coletivos ressignificando a vida para um amanhã melhor. Acreditr para reinventar soluções saudáveis de bem estar no dia-a-dia.

Saber utilizar a tecnologia como facilitadora de saberes diferentes. Possibilitar os recursos tecnologicos adequados para ocorrer a aprrendizagem, utilizar aplicativos e instrumentos que realmente ajudem ao SABER.

Plataformas de acesso como ZOOM, Google Classroom como ambientes virtuais para ocorrer momentos de formação, inovar a rotina da sala de aula.

Refletir e incluir condições a cultura a saberes diferente, situações do dia-a-dia interferem diretamente nas emoções e comportamento.

Sincronizar atividades de aprendizagem com o momento real, repeitando o meio e as emoções. Compreender os medos e superá-los transpondo o saber.

\section{Referências}

Antiqueira, L. M. O. R., \& Sekine, E. S. (2020). Os" erres" pós pandemia: princípios para sustentabilidade e cidadania. Revista Brasileira de Educação Ambiental (RevBEA), 15(4), 70-79.

Bacich, Lilian, Moran, José (Org.). Metodologias ativas para uma educação inovadora: uma abordagem teórico-prática. Porto Alegre: Penso, 2018. Brasil. Ministério da Educação. Lei no 9.394/96 de Diretrizes e Bases da Educação Nacional. Brasília: MEC, 1996.

Brasil. Secretaria de Educação Fundamental. Parâmetros Curriculares Nacionais: Educação Física. Brasília: MEC, 1998.

Brasil, Lei 8.069, de julho de 1990. "Estatuto da Criança e do Adolescente. ”Lei Federal.

Bregalda, Larissa; Do Valle Filho, Jorge GC. Síndrome de burnout um alerta na área da saúde. Revista Multidisciplinar em Saúde, v. 1, n. 3, p. 77-77, 2020.

Bzuneck, José Aloyseo. Emoções acadêmicas, autorregulação e seu impacto sobre motivação e aprendizagem. ETD-Educação Temática Digital, v. 20, n. 4, p. $1059-1075,2018$

dos Santos Junior, V. B., \& da Silva Monteiro, J. C. (2020). Educação e covid-19: as tecnologias digitais mediando a aprendizagem em tempos de pandemia. Revista Encantar-Educação, Cultura e Sociedade, 2, 01-15.

Ferreira, A. B. H. Mini Dicionário Aurélio: da Língua Portuguesa. $3^{\text {a }}$ ed. Rio de Janeiro: Editora Nova Fronteira, 1993.

Gil, A. C. (2008). Como elaborar projetos de pesquisa. 5. ed. São Paulo. Atlas. Pdf. 
Research, Society and Development, v. 11, n. 1, e27611124980, 2022

(CC BY 4.0) | ISSN 2525-3409 | DOI: http://dx.doi.org/10.33448/rsd-v11i1.24980

Guenther, M. (2020). Como será o amanhã? O mundo pós-pandemia. Revista Brasileira De Educação Ambiental (RevBEA), 15(4), 31-44.

Lerner, K., \& de Andréa Gradella, P. (2011). Mídia e pandemia: os sentidos do medo na cobertura de Influenza H1N1 nos jornais cariocas. Revista ECOPós, 14(2), 33-54.

Morales, Mario N. Experiencia de Aprendizaje Mediado. Aula proferida na Universidad del Mar no programa de doutorado. Chile janeiro de 2010.

Neto, Joaquim Maria Ferreira Antunes. Sobre ensino, aprendizagem e a sociedade da tecnologia: por que se refletir em tempo de pandemia?. Prospectus (ISSN: 2674-8576), v. 2, n. 1, 2020

Nóvoa, António. Educação 2021: para uma história do futuro. Educação, Sociedade \& Culturas, n. 41, p. 171-185, 2014.

Ornell, F. E. L. I. P. E., Schuch, J. B., Sordi, A. O., \& Kessler, F. H. (2020). Pandemia de medo e COVID-19: impacto na saúde mental e possíveis estratégicas. Revista debates in psychiatry.

Piaet, G. A formação do símbolo na criança: imitação, jogo e sonho, imagem e representação. Rio de Janeiro: Editora Zahar, 1975.

Resende, M. F. G. (2021). Tecnologia e educação. Revista Estudos e Negócios Academics, v. 1, n. 2, p. 68-74

Seixas, Sónia Raquel Pereira Malta Marruaz. "Da neurobiologia das relações precoces à neuroeducação." Interacções 30.10 (2014): $44-71$.

Vygotsky, L. S. A formação social da mente. São Paulo: Editora Martins Fontes, 1998. 